\title{
Brain-derived neurotrophic factor: a bridge between inflammation and neuroplasticity
}

\author{
Francesca Calabrese ${ }^{1}$, Andrea C. Rossetti ${ }^{1}$, Giorgio Racagni ${ }^{1}$, Peter Gass ${ }^{2}$, Marco A. Riva ${ }^{1}$ \\ and Raffaella Molteni ${ }^{1}$ * \\ 1 Department of Pharmacological and Biomolecular Sciences, Università degli Studi di Milano, Milan, Italy \\ 2 Department of Psychiatry and Psychotherapy, Research Group Animal Models in Psychiatry, Central Institute of Mental Health, Medical Faculty \\ Mannheim/Heidelberg University, Mannheim, Germany
}

\section{Edited by:}

Silvia Alboni, University of Modena and Reggio Emilia, Italy

Reviewed by:

Sasidhar Reddy Murikinati, Yale

University school of medicine, USA

Shawn Hayley, Carleton University,

Canada

Zheyu Chen, Shandong University,

China

\section{*Correspondence:}

Raffaella Molteni, Department of

Pharmacological and Biomolecular

Sciences, Università degli Studi di

Milano, Via Balzaretti 9, 20133

Milan, Italy

e-mail: raffaella.molteni@unimi.it
Cytokines are key regulatory mediators involved in the host response to immunological challenges, but also play a critical role in the communication between the immune and the central nervous system. For this, their expression in both systems is under a tight regulatory control. However, pathological conditions may lead to an overproduction of pro-inflammatory cytokines that may have a detrimental impact on central nervous system. In particular, they may damage neuronal structure and function leading to deficits of neuroplasticity, the ability of nervous system to perceive, respond and adapt to external or internal stimuli. In search of the mechanisms by which pro-inflammatory cytokines may affect this crucial brain capability, we will discuss one of the most interesting hypotheses: the involvement of the neurotrophin brain-derived neurotrophic factor (BDNF), which represents one of the major mediators of neuroplasticity.

Keywords: BDNF, neurogenesis, lipopolysaccaride, pro-inflammatory cytokines, depression

\section{NEUROPLASTICITY AND BRAIN-DERIVED NEUROTROPHIC FACTOR}

For many years the medical field held the belief that the brain did not make major changes after a certain point in time. It was fixed or set on a specific path. Today, in contrast, we know that the brain is actually capable of changing and developing throughout a lifetime. It is plastic or malleable, and the term neuroplasticity is used to describe this tendency for the brain to keep developing, changing, and potentially healing itself.

Specifically, neuroplasticity or neuronal plasticity refers to the ability of the nervous system to respond and adapt to environmental challenges and encompasses a series of functional and structural mechanisms that may lead to neuronal remodeling, formation of novel synapses and birth of new neurons. Neuronal plasticity is intimately linked to cellular responsiveness and may therefore be considered an index of the neuronal capability to adapt its function to a different demand. Failure of such mechanisms might enhance the susceptibility to environmental challenges, such as stress, and ultimately lead to psychopathology.

Among the genes responsive to neuronal activity, neurotrophic factors (NTFs), and in particular the neurotrophin family, play an important role. In fact, besides their classical role in supporting neuronal survival, NTFs finely modulate all the crucial steps of network construction, from neuronal migration to experience-dependent refinement of local connections (Poo, 2001). These functions were first reported based on the observation that, during the development of the nervous system, neuron survival depends on the limited amount of specific NTFs secreted by target cells (Huang and Reichardt, 2001). However, it is now well established that NTFs are important mediators of neuronal plasticity also in adulthood where they modulate axonal and dendritic growth and remodeling, membrane receptor trafficking, neurotransmitter release, synapse formation and function ( $\mathrm{Lu}$ et al., 2005). The neurotrophin brainderived neurotrophic factor (BDNF) has emerged as crucial mediator of neuronal plasticity, since it is abundant in brain regions particularly relevant for plasticity, but also because it shows a remarkable activity-dependent regulation of expression and secretion (Bramham and Messaoudi, 2005), suggesting that it might indeed bridge experience with enduring change in neuronal function. BDNF has a complex genomic structure, which results into a sophisticated organization in terms of transcriptional, translational and post-translational regulatory mechanisms (Aid et al., 2007). In particular, the rat BDNF gene- that is similar to the human gene-can generate nine distinct transcripts through the alternative splicing of 5' un-translated exons to a common 3' exon (IX), which encodes the BDNF protein (Aid et al., 2007). These transcripts have different distribution and/or translation efficacy and, more importantly, may sub-serve different functions. For example, transcripts that are primarily localized or targeted to dendrites may sustain local neurotrophin production, thus providing an effective mechanism to regulate synaptic structure and function (An et al., 2008; Wu et al., 2011). Since the transcription of the different isoforms is regulated by specific signaling pathways (Pruunsild et al., 2011), their investigation may provide useful information on the up-stream mechanisms contributing to the changes of BDNF gene expression. 
The mechanisms that lie downstream from NTFs and contribute to the maintenance of neuroplasticity are different i.e., adult neurogenesis and neuronal remodeling, but on the purpose of this mini-review we will focus only on adult neurogenesis, the process by which neurons are generated. Neurogenesis occurs under precise spatial and temporal control, but it can be modulated by both internal and external stimuli. Among these, several sources of data indicate the positive impact of BDNF on adult neurogenesis (Lee et al., 2002; Sairanen et al., 2005; Scharfman et al., 2005; Gass and Riva, 2007; Bergami et al., 2008; Chan et al., 2008; Li et al., 2008; Waterhouse et al., 2012), however in this review we will focus our attention on the effects of proinflammatory cytokines.

\section{NEUROGENESIS AND INFLAMMATORY STATE}

Neurogenesis has been defined as the process in which newborn neurons are generated from progenitors to functionally integrate in the neuronal network (Ming and Song, 2005; Balu and Lucki, 2009; Aimone et al., 2014). Actually, active neurogenesis take place, in the healthy central nervous system, only in two specific regions: neurons are continuously generated in the sub-ventricular zone (SVZ) and migrate into the olfactory bulb to become interneurons and, in parallel, neurogenesis occurs also in the sub-granular zone (SGZ) of the dentate gyrus of the hippocampus, where new granule neurons are continually generated. Depending on different stimuli, neural stem cells, located in so-called stem cell niches, could divide symmetrically, leading to the generation of two identical cells to maintain the pool of undifferentiated progenitors or, on the other hand, they can divide asymmetrically in order to generate an identical daughter cell and a second cell that starts to differentiate. The de novo formation and integration of new neurons into the existing circuitry is one of the various plastic changes that allow the adult brain to adapt to exogenous stimuli (Amrein et al., 2011). In particular, adult neurogenesis within the hippocampus could contribute to enhanced neural plasticity, a process that is fundamental for specific brain functions such as spatial learning, pattern discrimination, contextual memory and mood regulation (Clelland et al., 2009; Sahay et al., 2011; Denny et al., 2014). The important role of hippocampal neurogenesis is underlined by the fact that this system is altered after various types of negative stimuli such as stress, one of the major risk factors for psychiatric diseases. Specifically, repeated restraint and inescapable foot shock, two examples of physical stressors, inhibit one or more steps of adult neurogenesis in the dentate gyrus (Malberg and Duman, 2003; Pham et al., 2003); the social defeat paradigm leads to an inhibitory effect on cell proliferation and survival of newborn granule neurons in rodents (Czéh et al., 2002; Jun et al., 2012); and social isolation, which is associated with decreased neurogenesis and behavioral alterations in rodents, has been recently proven to be deleterious also for hippocampal neurogenesis and behavior in non human primates (Cinini et al., 2014).

As previously mentioned, neurogenesis is conditioned by a very complex microenvironment constituted by the vascular net, different growth and NTFs, changes in electrical and chemical environment and support by glial cells (Kohman and
Rhodes, 2013). In this scenario, neuroinflammation is emerging as one of the main actors. In fact the immune system, through cells within the brain (e.g., microglia) and the detrimental or the beneficial action of signaling molecules (proinflammatory or anti-inflammatory cytokines) could participate in the response to different exogenous and endogenous stimuli. The negative effects of neuroinflammation on neurogenesis could lead to impaired survival and proliferation of new neurons. For example, intracortical or intraperitoneal administration of lipopolysaccaride (LPS) from E. coli, an agent able to induce a strong immune response, decreases new neurons survival and the differentiation of new cells into neurons (Ekdahl et al., 2003; Monje et al., 2003). The consequences of inflammation on neurogenesis could have also functional implications for cognition. In fact, the impact of neuroinflammation could affect also the correct integration of newborn neurons into pre-existing circuits, through changes in cellular morphology and in electrophysiological properties (Jakubs et al., 2008) and reduction in recruitment into hippocampal networks encoding spatial information (Belarbi et al., 2012).

\section{THE IMPACT OF PRO-INFLAMMATORY CYTOKINES ON NEUROGENESIS}

Neuroinflammation has an important role in the pathophysiology of different acute or chronic CNS disorders such as cerebral ischemia, multiple sclerosis, Alzheimer's disease, Parkinson's disease and major depression (Wang and Jin, 2014). These diseases are characterized by the modulation of different mediators of inflammation and among them pro-inflammatory cytokines seem to play a key role. It is important to note that the same cytokines that in a physiological state are involved in the maintenance of neuronal integrity, may instead have detrimental effects under pathological conditions. Accordingly, the impact of the pro-inflammatory cytokines on neurogenesis depends on their concentration, on the specific cells activated (astrocytes and microglia) and on the presence of other factors secreted in the neurogenic niche (Eyre and Baune, 2012). The increase of proinflammatory cytokines is not only due to a direct inflammatory stimulus (infection or trauma), but it could be caused by environmental stimuli such as stress (García-Bueno et al., 2008). The main consequence of a dysregulation of cytokine levels within the brain is the production of inflammatory, oxidative and nitrosative molecules that could affect neurogenesis and the neural homeostasis (Kubera et al., 2011; Stepanichev et al., 2014).

The most common pro-inflammatory cytokines are IL- $1 \beta$, IL-6, TNF- $\alpha$ and IFN- $\gamma$ and here we will present some examples of the involvement of these molecules in the modulation of neurogenesis.

The main actions of IL- $1 \beta$ are the stimulation of immune cells to produce pro-inflammatory cytokines, the activation of microglia, and the regulation of growth factors activity (Audet and Anisman, 2013). Recently, IL-1 $\beta$ has been proven to influence hippocampal cytogenesis and neurogenesis in different ways: by direct interaction to its receptor (IL-1R1) and the consequent activation of the nuclear factor-kappa B (NFkB; Koo and Duman, 2008) or through the promotion of glucocorticoids secretion 
after the exposure to environmental stressors (Goshen et al., 2008). Moreover this cytokine has been proposed as the central mediator of antineurogenic effect of stress (Ben MenachemZidon et al., 2008). In fact the blockade of IL- $1 \beta$ signaling, using knockout mice for its receptor or administrating a IL-1R1 antagonist (IL-1Ra), prevents the decrease in neurogenesis observed after acute stressors such as footshock and immobilization in rats (Koo and Duman, 2008). Another relevant cytokine is IL6 that is involved in a multitude of neuroprotective functions. In physiological conditions IL-6 is able to activate pathways related to neural plasticity, neurogenesis, Long Term Potentiation, and memory (Eyre and Baune, 2012). On the other hand, this cytokine is also responsible of mediating synthesis of acute phase proteins, growth and differentiation of immune cells and regulation of pro-inflammatory factors (Audet and Anisman, 2013). Monje et al. demonstrated that the incubation of hippocampal progenitor cells with recombinant IL-6 decreases neurogenesis by half and reduces neuronal differentiation in favor of astrocytogenesis (Monje et al., 2003; Taga and Fukuda, 2005), an effect mediated by the activation of the JAK/STAT3 pathway via gp130 (Namihira and Nakashima, 2013). Tumor necrosis factor-alpha (TNF- $\alpha)$ is a potent inductor of inflammation and has been linked to decreased neural stem cell proliferation, decreased neurogenesis, neurodegenerative processes, apoptosis and excitotoxicity (Dantzer et al., 2008; Belarbi et al., 2012), but also to the modulation of synaptic strength and synaptic preservation through the increase of the $\alpha$-amino-3-hydroxy-5methyl-4-isoxazolepropionic acid (AMPA) receptors (Khairova et al., 2009). The negative action of TNF- $\alpha$ on neurogenesis is mediated by the activation of its receptor TNF-R1, conversely the interaction with TNF-R2 increases proliferation and survival of newborn neurons, as demonstrated by using transgenic animals with deletion of TNF-R1 or TNF-R2 (Iosif et al., 2006). A similar result on the beneficial role of TNF-R2 activation after irradiation injury has been recently reported (Chen and Palmer, 2013). Moreover, the up-regulation of TNF- $\alpha$ observed in the hippocampus of adult rats pre-exposed to maternal deprivation has been associated with impaired memory consolidation (Pinheiro et al., 2014). IFN- $\gamma$ is a pro-inflammatory cytokine with in vitro anti-neurogenic effect able to reduce the number of neural stem cells. The negative action of IFN- $\gamma$ on neurogenesis may be exerted by the activation of the caspase $3 / 7$, the upregulation of sonic hedgehog $(\mathrm{SHH})$ pathway and promotion of an abnormal marker profile of neural stem cells, expressing both GFAP and $\beta$ III tubulin (Walter et al., 2011). Nevertheless, IFN$\gamma$ may also exerts positive action on neurogenesis. For example, it enhances neurogenesis in dentate gyrus of adult mice and ameliorates spatial learning and memory performance (Baron et al., 2008). These observations suggest that IFN- $\gamma$ has different effects depending on tissues involved and on the neurogenic process involved.

Taken together, all these studies indicate that a dysregulation of pro-inflammatory cytokines may have a detrimental effect on neurogenesis and point out the importance of neuroinflammation in the microenvironment around neural stem cell development. On this context, the identification and characterization of the mechanisms by which pro-inflammatory cytokines affect neurogenesis are crucial to develop new strategies to maintain the proper function of stem cell niches within the brain.

\section{THE IMPACT OF PRO-INFLAMMATORY CYTOKINES ON BDNF}

Given the role of BDNF as an important mediator of neuroplasticity and on the basis of its positive contribution on neurogenesis in contrast to the detrimental effect of pro-inflammatory cytokines, we may hypothesize that one of the mechanisms by which inflammation may affect brain function could involve BDNF modulation.

Several in vivo studies demonstrated that inflammation clearly affects the expression of BDNF within the brain. In particular, it has been reported that the administration of pro-inflammatory cytokines or of the cytokine-inducer lipopolysaccharide, (LPS; Raetz and Whitfield, 2002) causes a significant reduction of BDNF gene expression. For example, the mRNA levels of BDNF were significantly decreased in the rat hippocampus $4 \mathrm{~h}$ after intraperitoneal injection of IL-1 $\beta$ or LPS (Lapchak et al., 1993) and a similar reduction was also observed in several cortical regions and at protein level (Guan and Fang, 2006; Schnydrig et al., 2007). Interestingly, the effect of the systemic inflammatory challenge was not restricted to BDNF: other neurotrophins such as nerve growth factor (NGF) and neurotrophin-3 (NT-3) were similarly reduced although with different magnitude (Guan and Fang, 2006).

Recently, it has also been evaluated the effect of peripheral immune challenge on the different BDNF transcripts, finding that the expression of exons I, II, and IV in the dentate gyrus was reduced in the CA1 and in the dentate gyrus of rats acutely treated with E. coli (Chapman et al., 2012), indicating that inflammation may affect specific isoforms of the neurotrophin. Nevertheless, there is a critical lack of information about the effects of inflammation on the expression of specific BDNF transcripts and further studies are demanded in order to clarify the mechanisms involved in the modulation of the neurotrophin by the immune/inflammatory system.

The negative impact of inflammation on BDNF has important implications for a number of pathological conditions. For example, it is known that pro-inflammatory cytokines compromise hippocampus-dependent memory (Pugh et al., 1998), spatial memory (Arai et al., 2001) and increase apoptosis in the brain (Nolan et al., 2003), features that are involved in many aging-associated pathologies and neurodegenerative diseases. In addition, it is well-know that the activation of the immune/inflammatory system may contribute to the development of different psychiatric diseases such as schizophrenia and major depression (Dantzer et al., 2008; Miller et al., 2009; Leonard and Maes, 2012; Zunszain et al., 2013). Regarding depression, there are three main supportive evidences: first, depressed subjects exhibit increased levels of inflammatory markers both in the periphery and in brain (Howren et al., 2009; Dowlati et al., 2010); second: several pathologies associated with moderate inflammatory grade present high depression comorbidity (Benton et al., 2007); third: a high percentage of patients with cancer or hepatitis $\mathrm{C}$ treated with interferon-alpha develop major depression (Valentine and Meyers, 2005; Udina et al., 2012). In addition, it has to be noted that animals exposed to immune challenges 


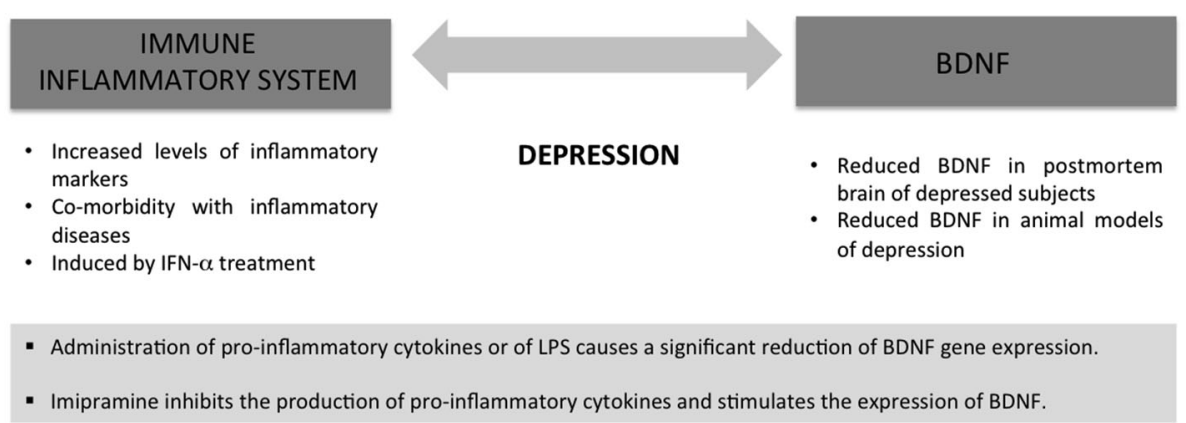

FIGURE 1 | Immune/inflammatory alterations and changes in BDNF expression and function are characteristic of the same pathologies, for example major depression, suggesting a cross-talk between the two systems.

display depressive-like behaviors (Yirmiya, 1996; Frenois et al., 2007) that can be normalized, or at least limited, by antidepressant treatment (Yirmiya et al., 2001). In contrast, mice that lack IL-6 are stress resistant and have a reduced disposition for depressivelike behaviors (Chourbaji et al., 2006). The mechanism underlying the anti-inflammatory properties of antidepressant is still unknown and is beyond the aim of our mini-review. However, the results of several in vitro and in vivo studies indicate that these drugs are able to modulate cytokine functioning through their effects on intracellular cyclic adenosyl monophosphate, serotonin metabolism, the hypothalamo-pituitary-adrenocortical axis (Janssen et al., 2010; Walker, 2013; Leonard, 2014).

It is important to consider that the immune/inflammatory alterations previously described are actually in parallel with changes on BDNF expression and function (Figure 1). Indeed, BDNF has a well recognized role in the etiology as well as in the treatment response of patients affected by different psychiatric disorders including major depression (Pezet and Malcangio, 2004; Duman and Monteggia, 2006). For example, decreased expression of the neurotrophin has been found in the hippocampus and prefrontal cortex of postmortem brains from depressed and suicide victims (Dwivedi et al., 2003). Moreover, BDNF mRNA levels are reduced in the brain of genetic animal models of depression (Ridder et al., 2005; Calabrese et al., 2010; Molteni et al., 2010a,c) as well as in animal models based on the environmental component of the disease (Duman and Monteggia, 2006; Tsankova et al., 2006; Chourbaji et al., 2012).

All these findings support the possibility that inflammation contributes to the development of depression by compromising neuroplasticity via reduction of BDNF. In agreement with this line of thinking, it has been recently reported that intranigral LPS infusion induced an anxious and depressive phenotype in the rat that was associated with decreased hippocampal expression of BDNF (Hritcu and Gorgan, 2014).

In order to have a unequivocal proof for causality, inflammation-dependent decrease of BDNF should be normalized or at least attenuated by antidepressant treatment, as occurs in experimental models where BDNF expression is up-regulated in response to prolonged treatment with different antidepressant drugs (Schmidt and Duman, 2007; Calabrese et al., 2010; Molteni et al., 2010b; Park et al., 2011).

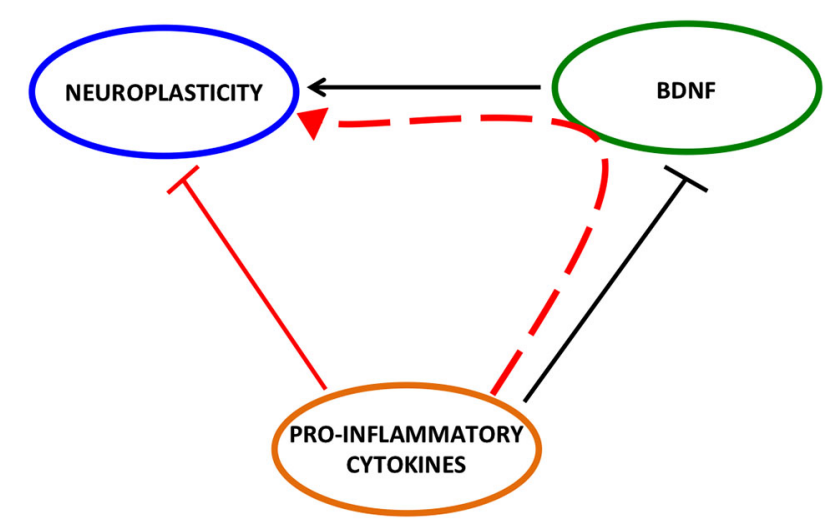

FIGURE 2 | Detrimental effect of pro-inflammatory cytokines on neuroplasticity may be mediated by BDNF

Although there are only few data on this issue, it has been demonstrated that the incubation of rat neural stem cells with the antidepressant imipramine inhibits the production of proinflammatory cytokines, whereas stimulates the expression of BDNF (Peng et al., 2008), nevertheless, further studies are demanded to clarify this issue in order to provide unequivocal proof for causality.

\section{CONCLUDING REMARKS}

In conclusion, we attempted to provide evidence on the possibility that one of the mechanisms underlying the negative impact of pro-inflammatory cytokines on neuroplasticity is the reduction of BDNF expression and function (Figure 2).

Although several data support this hypothesis, further studies are demanded to better clarify how it occurs. A number of result points out a key role for the pro-inflammatory cytokine IL- $1 \beta$ as it has been shown that the inhibitory effect of stress paradigms on cerebral BDNF expression may be attenuated by intracerebroventricular injection of IL-1 receptor antagonist (Barrientos et al., 2003). However, how this -or others- pro-inflammatory cytokine affects the neurotrophin is still not well understood. Since in vitro and in vivo studies indicate that glucocorticoids decrease the neurotrophin (Hansson et al., 2003; Gubba et al., 2004; 
Hansson and Fuxe, 2008), one possibility is the involvement of the Hypotalamus-Pituitary-Axis (HPA), which is strongly stimulated by pro-inflammatory cytokines (Rivest, 2010). However, we have to be aware that pro-inflammatory cytokines act on a plethora of different targets, for example the neurotransmitters glutamate (Viviani et al., 2007; Di Filippo et al., 2013) and GABA (Galic et al., 2012), both able to modulate BDNF. In this context, it is feasible that the effect of the immune/inflammatory system on BDNF results from the integration of multiple mechanisms. A better knowledge of these events may be useful to develop new therapeutic strategies aimed to normalize, or at least ameliorate, the pathological consequences of the negative impact of inflammation on brain structure and function.

\section{REFERENCES}

Aid, T., Kazantseva, A., Piirsoo, M., Palm, K., and Timmusk, T. (2007). Mouse and rat BDNF gene structure and expression revisited. J. Neurosci. Res. 85, 525-535. doi: 10.1002/jnr.21139

Aimone, J. B., Li, Y., Lee, S. W., Clemenson, G. D., Deng, W., and Gage, F. H. (2014). Regulation and function of adult neurogenesis: from genes to cognition. Physiol. Rev. 94, 991-1026. doi: 10.1152/physrev.00004.2014

Amrein, I., Isler, K., and Lipp, H. P. (2011). Comparing adult hippocampal neurogenesis in mammalian species and orders: influence of chronological age and life history stage. Eur. J. Neurosci. 34, 978-987. doi: 10.1111/j.1460-9568. 2011.07804.x

An, J. J., Gharami, K., Liao, G. Y., Woo, N. H., Lau, A. G., Vanevski, F., et al. (2008). Distinct role of long 3/ UTR BDNF mRNA in spine morphology and synaptic plasticity in hippocampal neurons. Cell 134, 175-187. doi: 10.1016/j.cell.2008. 05.045

Arai, K., Matsuki, N., Ikegaya, Y., and Nishiyama, N. (2001). Deterioration of spatial learning performances in lipopolysaccharide-treated mice. Jpn. J. Pharmacol. 87, 195-201. doi: 10.1254/jjp.87.195

Audet, M. C., and Anisman, H. (2013). Interplay between pro-inflammatory cytokines and growth factors in depressive illnesses. Front. Cell. Neurosci. 7:68. doi: 10.3389/fncel.2013.00068

Balu, D. T., and Lucki, I. (2009). Adult hippocampal neurogenesis: regulation, functional implications and contribution to disease pathology. Neurosci. Biobehav. Rev. 33, 232-252. doi: 10.1016/j.neubiorev.2008.08.007

Baron, R., Nemirovsky, A., Harpaz, I., Cohen, H., Owens, T., and Monsonego, A. (2008). IFN-gamma enhances neurogenesis in wild-type mice and in a mouse model of Alzheimer's disease. FASEB J. 22, 2843-2852. doi: 10.1096/fj. 08-105866

Barrientos, R. M., Sprunger, D. B., Campeau, S., Higgins, E. A., Watkins, L. R., Rudy, J. W., et al. (2003). Brain-derived neurotrophic factor mRNA downregulation produced by social isolation is blocked by intrahippocampal interleukin-1 receptor antagonist. Neuroscience 121, 847-853. doi: 10 . 1016/s0306-4522(03)00564-5

Belarbi, K., Arellano, C., Ferguson, R., Jopson, T., and Rosi, S. (2012). Chronic neuroinflammation impacts the recruitment of adult-born neurons into behaviorally relevant hippocampal networks. Brain Behav. Immun. 26, 18-23. doi: 10. 1016/j.bbi.2011.07.225

Ben Menachem-Zidon, O., Goshen, I., Kreisel, T., Ben Menahem, Y., Reinhartz, E., Ben Hur, T., et al. (2008). Intrahippocampal transplantation of transgenic neural precursor cells overexpressing interleukin-1 receptor antagonist blocks chronic isolation-induced impairment in memory and neurogenesis. Neuropsychopharmacology 33, 2251-2262. doi: 10.1038/sj.npp.1301606

Benton, T., Staab, J., and Evans, D. L. (2007). Medical co-morbidity in depressive disorders. Ann. Clin. Psychiatry 19, 289-303. doi: 10.1080/104012307016 53542

Bergami, M., Rimondini, R., Santi, S., Blum, R., Götz, M., and Canossa, M. (2008). Deletion of TrkB in adult progenitors alters newborn neuron integration into hippocampal circuits and increases anxiety-like behavior. Proc. Natl. Acad. Sci. US A 105, 15570-15575. doi: 10.1073/pnas.0803702105

Bramham, C. R., and Messaoudi, E. (2005). BDNF function in adult synaptic plasticity: the synaptic consolidation hypothesis. Prog. Neurobiol. 76, 99-125. doi: 10.1016/j.pneurobio.2005.06.003
Calabrese, F., Molteni, R., Cattaneo, A., Macchi, F., Racagni, G., Gennarelli, M., et al. (2010). Long-Term duloxetine treatment normalizes altered brain-derived neurotrophic factor expression in serotonin transporter knockout rats through the modulation of specific neurotrophin isoforms. Mol. Pharmacol. 77, 846-853. doi: 10.1124/mol.109.063081

Chan, J. P., Cordeira, J., Calderon, G. A., Iyer, L. K., and Rios, M. (2008). Depletion of central BDNF in mice impedes terminal differentiation of new granule neurons in the adult hippocampus. Mol. Cell. Neurosci 39, 372-383. doi: 10. 1016/j.mcn.2008.07.017

Chapman, T. R., Barrientos, R. M., Ahrendsen, J. T., Hoover, J. M., Maier, S. F., and Patterson, S. L. (2012). Aging and infection reduce expression of specific brain-derived neurotrophic factor mRNAs in hippocampus. Neurobiol. Aging 33, 832.e1-832.e14. doi: 10.1016/j.neurobiolaging.2011.07.015

Chen, Z., and Palmer, T. D. (2013). Differential roles of TNFR1 and TNFR2 signaling in adult hippocampal neurogenesis. Brain Behav. Immun. 30, 45-53. doi: 10.1016/j.bbi.2013.01.083

Chourbaji, S., Hörtnagl, H., Molteni, R., Riva, M. A., Gass, P., and Hellweg, R. (2012). The impact of environmental enrichment on sex-specific neurochemical circuitries-effects on brain-derived neurotrophic factor and the serotonergic system. Neuroscience 220, 267-276. doi: 10.1016/j.neuroscience.2012.06.016

Chourbaji, S., Urani, A., Inta, I., Sanchis-Segura, C., Brandwein, C., Zink, M., et al. (2006). IL-6 knockout mice exhibit resistance to stress-induced development of depression-like behaviors. Neurobiol. Dis. 23, 587-594. doi: 10.1016/j.nbd.2006. 05.001

Cinini, S. M., Barnabe, G. F., Galvão-Coelho, N., de Medeiros, M. A., PerezMendes, P., Sousa, M. B., et al. (2014). Social isolation disrupts hippocampal neurogenesis in young non-human primates. Front. Neurosci. 8:45. doi: 10. 3389/fnins.2014.00045

Clelland, C. D., Choi, M., Romberg, C., Clemenson, G. D. Jr., Fragniere, A., Tyers, P., et al. (2009). A functional role for adult hippocampal neurogenesis in spatial pattern separation. Science 325, 210-213. doi: 10.1126/science.1173215

Czéh, B., Welt, T., Fischer, A. K., Erhardt, A., Schmitt, W., Müller, M. B., et al. (2002). Chronic psychosocial stress and concomitant repetitive transcranial magnetic stimulation: effects on stress hormone levels and adult hippocampal neurogenesis. Biol. Psychiatry 52, 1057-1065. doi: 10.1016/s00063223(02)01457-9

Dantzer, R., O'connor, J. C., Freund, G. G., Johnson, R. W., and Kelley, K. W. (2008). From inflammation to sickness and depression: when the immune system subjugates the brain. Nat. Rev. Neurosci. 9, 46-56. doi: 10.1038/nrn2297

Denny, C. A., Kheirbek, M. A., Alba, E. L., Tanaka, K. F., Brachman, R. A., Laughman, K. B., et al. (2014). Hippocampal memory traces are differentially modulated by experience, time, and adult neurogenesis. Neuron 83, 189-201. doi: 10.1016/j.neuron.2014.05.018

Di Filippo, M., Chiasserini, D., Gardoni, F., Viviani, B., Tozzi, A., Giampà, C., et al. (2013). Effects of central and peripheral inflammation on hippocampal synaptic plasticity. Neurobiol. Dis. 52, 229-236. doi: 10.1016/j.nbd.2012.12.009

Dowlati, Y., Herrmann, N., Swardfager, W., Liu, H., Sham, L., Reim, E. K., et al. (2010). A meta-analysis of cytokines in major depression. Biol. Psychiatry 67, 446-457. doi: 10.1016/j.biopsych.2009.09.033

Duman, R. S., and Monteggia, L. M. (2006). A neurotrophic model for stressrelated mood disorders. Biol. Psychiatry 59, 1116-1127. doi: 10.1016/j.biopsych. 2006.02.013

Dwivedi, Y., Rizavi, H. S., Conley, R. R., Roberts, R. C., Tamminga, C. A., and Pandey, G. N. (2003). Altered gene expression of brain-derived neurotrophic factor and receptor tyrosine kinase B in postmortem brain of suicide subjects. Arch. Gen. Psychiatry 60, 804-815. doi: 10.1001/archpsyc.60.8.804

Ekdahl, C. T., Claasen, J. H., Bonde, S., Kokaia, Z., and Lindvall, O. (2003). Inflammation is detrimental for neurogenesis in adult brain. Proc. Natl. Acad. Sci. U S A 100, 13632-13637. doi: 10.1073/pnas.2234031100

Eyre, H., and Baune, B. T. (2012). Neuroplastic changes in depression: a role for the immune system. Psychoneuroendocrinology 37, 1397-1416. doi: 10.1016/j. psyneuen.2012.03.019

Frenois, F., Moreau, M., O'connor, J., Lawson, M., Micon, C., Lestage, J., et al. (2007). Lipopolysaccharide induces delayed FosB/DeltaFosB immunostaining within the mouse extended amygdala, hippocampus and hypothalamus, that parallel the expression of depressive-like behavior. Psychoneuroendocrinology 32, 516-531. doi: 10.1016/j.psyneuen.2007.03.005

Galic, M. A., Riazi, K., and Pittman, Q. J. (2012). Cytokines and brain excitability. Front. Neuroendocrinol. 33, 116-125. doi: 10.1016/j.yfrne.2011.12.002 
García-Bueno, B., Caso, J. R., and Leza, J. C. (2008). Stress as a neuroinflammatory condition in brain: damaging and protective mechanisms. Neurosci. Biobehav. Rev. 32, 1136-1151. doi: 10.1016/j.neubiorev.2008.04.001

Gass, P., and Riva, M. A. (2007). CREB, neurogenesis and depression. Bioessays 29, 957-961. doi: 10.1002/bies.20658

Goshen, I., Kreisel, T., Ben-Menachem-Zidon, O., Licht, T., Weidenfeld, J., BenHur, T., et al. (2008). Brain interleukin-1 mediates chronic stress-induced depression in mice via adrenocortical activation and hippocampal neurogenesis suppression. Mol. Psychiatry 13, 717-728. doi: 10.1038/sj.mp.4002055

Guan, Z., and Fang, J. (2006). Peripheral immune activation by lipopolysaccharide decreases neurotrophins in the cortex and hippocampus in rats. Brain Behav. Immun. 20, 64-71. doi: 10.1016/j.bbi.2005.04.005

Gubba, E. M., Fawcett, J. W., and Herbert, J. (2004). The effects of corticosterone and dehydroepiandrosterone on neurotrophic factor mRNA expression in primary hippocampal and astrocyte cultures. Brain Res. Mol. Brain Res. 127, 48-59. doi: 10.1016/j.molbrainres.2004.05.004

Hansson, A. C., and Fuxe, K. (2008). Time-course of immediate early gene expression in hippocampal subregions of adrenalectomized rats after acute corticosterone challenge. Brain Res. 1215, 1-10. doi: 10.1016/j.brainres.2008. 03.080

Hansson, A. C., Sommer, W., Rimondini, R., Andbjer, B., Strömberg, I., and Fuxe, K. (2003). c-fos reduces corticosterone-mediated effects on neurotrophic factor expression in the rat hippocampal CA1 region. J. Neurosci. 23, 6013-6022.

Howren, M. B., Lamkin, D. M., and Suls, J. (2009). Associations of depression with C-reactive protein, IL-1 and IL-6: a meta-analysis. Psychosom. Med. 71, 171-186. doi: 10.1097/psy.0b013e3181907clb

Hritcu, L., and Gorgan, L. D. (2014). Intranigral lipopolysaccharide induced anxiety and depression by altered BDNF mRNA expression in rat hippocampus. Prog. Neuropsychopharmacol. Biol. Psychiatry 51, 126-132. doi: 10.1016/j.pnpbp. 2014.01.016

Huang, E. J., and Reichardt, L. F. (2001). Neurotrophins: roles in neuronal development and function. Annu. Rev. Neurosci. 24, 677-736. doi: 10.1146/annurev. neuro.24.1.677

Iosif, R. E., Ekdahl, C. T., Ahlenius, H., Pronk, C. J., Bonde, S., Kokaia, Z., et al. (2006). Tumor necrosis factor receptor 1 is a negative regulator of progenitor proliferation in adult hippocampal neurogenesis. J. Neurosci. 26, 9703-9712. doi: 10.1523/jneurosci.2723-06.2006

Jakubs, K., Bonde, S., Iosif, R. E., Ekdahl, C. T., Kokaia, Z., Kokaia, M., et al. (2008). Inflammation regulates functional integration of neurons born in adult brain. $J$. Neurosci. 28, 12477-12488. doi: 10.1523/jneurosci.3240-08.2008

Janssen, D. G., Caniato, R. N., Verster, J. C., and Baune, B. T. (2010). A psychoneuroimmunological review on cytokines involved in antidepressant treatment response. Hum. Psychopharmacol. 25, 201-215. doi: 10.1002/hup.1103

Jun, H., Mohammed Qbsim Hussaini, S., Rigby, M. J., and Jang, M. H. (2012). Functional role of adult hippocampal neurogenesis as a therapeutic strategy for mental disorders. Neural Plast. 2012:854285. doi: 10.1155/2012/ 854285

Khairova, R. A., Machado-Vieira, R., Du, J., and Manji, H. K. (2009). A potential role for pro-inflammatory cytokines in regulating synaptic plasticity in major depressive disorder. Int. J. Neuropsychopharmacol. 12, 561-578. doi: 10. 1017/s1461145709009924

Kohman, R. A., and Rhodes, J. S. (2013). Neurogenesis, inflammation and behavior. Brain Behav. Immun. 27, 22-32. doi: 10.1016/j.bbi.2012.09.003

Koo, J. W., and Duman, R. S. (2008). IL-1beta is an essential mediator of the antineurogenic and anhedonic effects of stress. Proc. Natl. Acad. Sci. U S A 105, 751-756. doi: 10.1073/pnas.0708092105

Kubera, M., Obuchowicz, E., Goehler, L., Brzeszcz, J., and Maes, M. (2011). In animal models, psychosocial stress-induced (neuro)inflammation, apoptosis and reduced neurogenesis are associated to the onset of depression. Prog. Neuropsychopharmacol. Biol. Psychiatry 35, 744-759. doi: 10.1016/j.pnpbp.2010. 08.026

Lapchak, P. A., Araujo, D. M., and Hefti, F. (1993). Systemic interleukin-1 beta decreases brain-derived neurotrophic factor messenger RNA expression in the rat hippocampal formation. Neuroscience 53, 297-301. doi: 10.1016/03064522(93)90196-m

Lee, J., Duan, W., and Mattson, M. P. (2002). Evidence that brain-derived neurotrophic factor is required for basal neurogenesis and mediates, in part, the enhancement of neurogenesis by dietary restriction in the hippocampus of adult mice. J. Neurochem. 82, 1367-1375. doi: 10.1046/j.1471-4159.2002.01085.x
Leonard, B. E. (2014). Impact of inflammation on neurotransmitter changes in major depression: an insight into the action of antidepressants. Prog. Neuropsychopharmacol. Biol. Psychiatry 48, 261-267. doi: 10.1016/j.pnpbp.2013. 10.018

Leonard, B., and Maes, M. (2012). Mechanistic explanations how cell-mediated immune activation, inflammation and oxidative and nitrosative stress pathways and their sequels and concomitants play a role in the pathophysiology of unipolar depression. Neurosci. Biobehav. Rev. 36, 764-785. doi: 10.1016/j.neubiorev. 2011.12.005

Li, Y., Luikart, B. W., Birnbaum, S., Chen, J., Kwon, C. H., Kernie, S. G., et al. (2008). TrkB regulates hippocampal neurogenesis and governs sensitivity to antidepressive treatment. Neuron 59, 399-412. doi: 10.1016/j.neuron.2008. 06.023

Lu, B., Pang, P. T., and Woo, N. H. (2005). The yin and yang of neurotrophin action. Nat. Rev. Neurosci. 6, 603-614. doi: 10.1038/nrn1726

Malberg, J. E., and Duman, R. S. (2003). Cell proliferation in adult hippocampus is decreased by inescapable stress: reversal by fluoxetine treatment. Neuropsychopharmacology 28, 1562-1571. doi: 10.1038/sj.npp.1300234

Miller, A. H., Maletic, V., and Raison, C. L. (2009). Inflammation and its discontents: the role of cytokines in the pathophysiology of major depression. Biol. Psychiatry 65, 732-741. doi: 10.1016/j.biopsych.2008.11.029

Ming, G. L., and Song, H. (2005). Adult neurogenesis in the mammalian central nervous system. Annu. Rev. Neurosci. 28, 223-250. doi: 10.1146/annurev.neuro. 28.051804.101459

Molteni, R., Calabrese, F., Chourbaji, S., Brandwein, C., Racagni, G., Gass, P., et al. (2010a). Depression-prone mice with reduced glucocorticoid receptor expression display an altered stress-dependent regulation of brain-derived neurotrophic factor and activity-regulated cytoskeleton-associated protein. J. Psychopharmacol. 24, 595-603. doi: 10.1177/0269881108099815

Molteni, R., Calabrese, F., Pisoni, S., Gabriel, C., Mocaer, E., Racagni, G., et al. (2010b). Synergistic mechanisms in the modulation of the neurotrophin BDNF in the rat prefrontal cortex following acute agomelatine administration. World J. Biol. Psychiatry 11, 148-153. doi: 10.3109/156229709034 47659

Molteni, R., Cattaneo, A., Calabrese, F., Macchi, F., Olivier, J. D., Racagni, G., et al. (2010c). Reduced function of the serotonin transporter is associated with decreased expression of BDNF in rodents as well as in humans. Neurobiol. Dis. 37, 747-755. doi: 10.1016/j.nbd.2009.12.014

Monje, M. L., Toda, H., and Palmer, T. D. (2003). Inflammatory blockade restores adult hippocampal neurogenesis. Science 302, 1760-1765. doi: 10.1126/science. 1088417

Namihira, M., and Nakashima, K. (2013). Mechanisms of astrocytogenesis in the mammalian brain. Curr. Opin. Neurobiol. 23, 921-927. doi: 10.1016/j.conb.2013. 06.002

Nolan, Y., Vereker, E., Lynch, A. M., and Lynch, M. A. (2003). Evidence that lipopolysaccharide-induced cell death is mediated by accumulation of reactive oxygen species and activation of p38 in rat cortex and hippocampus. Exp. Neurol. 184, 794-804. doi: 10.1016/s0014-4886(03)00301-7

Park, S. W., Phuong, V. T., Lee, C. H., Lee, J. G., Seo, M. K., Cho, H. Y., et al. (2011). Effects of antipsychotic drugs on BDNF, GSK-3beta and beta-catenin expression in rats subjected to immobilization stress. Neurosci. Res. 71, 335-340. doi: 10. 1016/j.neures.2011.08.010

Peng, C. H., Chiou, S. H., Chen, S. J., Chou, Y. C., Ku, H. H., Cheng, C. K., et al. (2008). Neuroprotection by Imipramine against lipopolysaccharide-induced apoptosis in hippocampus-derived neural stem cells mediated by activation of BDNF and the MAPK pathway. Eur. Neuropsychopharmacol. 18, 128-140. doi: 10.1016/j.euroneuro.2007.05.002

Pezet, S., and Malcangio, M. (2004). Brain-derived neurotrophic factor as a drug target for CNS disorders. Expert Opin. Ther. Targets 8, 391-399. doi: 10. 1517/14728222.8.5.391

Pham, K., Nacher, J., Hof, P. R., and Mcewen, B. S. (2003). Repeated restraint stress suppresses neurogenesis and induces biphasic PSA-NCAM expression in the adult rat dentate gyrus. Eur. J. Neurosci. 17, 879-886. doi: 10.1046/j.1460-9568. 2003.02513.x

Pinheiro, R. M., de Lima, M. N., Portal, B. C., Busato, S. B., Falavigna, L., Ferreira, R. D., et al. (2014). Long-lasting recognition memory impairment and alterations in brain levels of cytokines and BDNF induced by maternal deprivation: effects of valproic acid and topiramate. J. Neural Transm. doi: 10. 1007/s00702-014-1303-2. [Epub ahead of print]. 
Poo, M. M. (2001). Neurotrophins as synaptic modulators. Nat. Rev. Neurosci. 2, 24-32. doi: 10.1038/35049004

Pruunsild, P., Sepp, M., Orav, E., Koppel, I., and Timmusk, T. (2011). Identification of cis-elements and transcription factors regulating neuronal activity-dependent transcription of human BDNF gene. J. Neurosci. 31, 32953308. doi: 10.1523/jneurosci.4540-10.2011

Pugh, C. R., Kumagawa, K., Fleshner, M., Watkins, L. R., Maier, S. F., and Rudy, J. W. (1998). Selective effects of peripheral lipopolysaccharide administration on contextual and auditory-cue fear conditioning. Brain Behav. Immun. 12, 212 229. doi: $10.1006 /$ brbi.1998.0524

Raetz, C. R., and Whitfield, C. (2002). Lipopolysaccharide endotoxins. Annu. Rev. Biochem. 71, 635-700. doi: 10.1146/annurev.biochem.71.110601.135414

Ridder, S., Chourbaji, S., Hellweg, R., Urani, A., Zacher, C., Schmid, W., et al. (2005). Mice with genetically altered glucocorticoid receptor expression show altered sensitivity for stress-induced depressive reactions. J. Neurosci. 25, 62436250. doi: 10.1523/jneurosci.0736-05.2005

Rivest, S. (2010). Interactions between the immune and neuroendocrine systems. Prog. Brain Res. 181, 43-53. doi: 10.1016/S0079-6123(08)81004-7

Sahay, A., Scobie, K. N., Hill, A. S., O'carroll, C. M., Kheirbek, M. A., Burghardt, N. S., et al. (2011). Increasing adult hippocampal neurogenesis is sufficient to improve pattern separation. Nature 472, 466-470. doi: 10.1038/nature09817

Sairanen, M., Lucas, G., Ernfors, P., Castrén, M., and Castrén, E. (2005). Brainderived neurotrophic factor and antidepressant drugs have different but coordinated effects on neuronal turnover, proliferation and survival in the adult dentate gyrus. J. Neurosci. 25, 1089-1094. doi: 10.1523/jneurosci.3741-04.2005

Scharfman, H., Goodman, J., Macleod, A., Phani, S., Antonelli, C., and Croll, S. (2005). Increased neurogenesis and the ectopic granule cells after intrahippocampal BDNF infusion in adult rats. Exp. Neurol. 192, 348-356. doi: 10. 1016/j.expneurol.2004.11.016

Schmidt, H. D., and Duman, R. S. (2007). The role of neurotrophic factors in adult hippocampal neurogenesis, antidepressant treatments and animal models of depressive-like behavior. Behav. Pharmacol. 18, 391-418. doi: 10.1097/fbp. ob013e3282ee2aa8

Schnydrig, S., Korner, L., Landweer, S., Ernst, B., Walker, G., Otten, U., et al. (2007). Peripheral lipopolysaccharide administration transiently affects expression of brain-derived neurotrophic factor, corticotropin and proopiomelanocortin in mouse brain. Neurosci. Lett. 429, 69-73. doi: 10.1016/j.neulet.2007.09.067

Stepanichev, M., Dygalo, N. N., Grigoryan, G., Shishkina, G. T., and Gulyaeva, N. (2014). Rodent models of depression: neurotrophic and neuroinflammatory biomarkers. Biomed Res. Int. 2014:932757. doi: 10.1155/2014/932757

Taga, T., and Fukuda, S. (2005). Role of IL-6 in the neural stem cell differentiation. Clin. Rev. Allergy Immunol. 28, 249-256. doi: 10.1385/criai:28:3:249

Tsankova, N. M., Berton, O., Renthal, W., Kumar, A., Neve, R. L., and Nestler, E. J. (2006). Sustained hippocampal chromatin regulation in a mouse model of depression and antidepressant action. Nat. Neurosci. 9, 519-525. doi: 10. $1038 / \mathrm{nn} 1659$

Udina, M., Castellví, P., Moreno-España, J., Navinés, R., Valdés, M., Forns, X., et al. (2012). Interferon-induced depression in chronic hepatitis C: a systematic review and meta-analysis. J. Clin. Psychiatry 73, 1128-1138. doi: 10.4088/jcp. $12 \mathrm{r} 07694$
Valentine, A. D., and Meyers, C. A. (2005). Neurobehavioral effects of interferon therapy. Curr. Psychiatry Rep. 7, 391-395. doi: 10.1007/s11920-0050042-3

Viviani, B., Gardoni, F., and Marinovich, M. (2007). Cytokines and neuronal ion channels in health and disease. Int. Rev. Neurobiol. 82, 247-263. doi: 10. 1016/s0074-7742(07)82013-7

Walker, F. R. (2013). A critical review of the mechanism of action for the selective serotonin reuptake inhibitors: do these drugs possess anti-inflammatory properties and how relevant is this in the treatment of depression? Neuropharmacology 67, 304-317. doi: 10.1016/j.neuropharm.2012.10.002

Walter, J., Honsek, S. D., Illes, S., Wellen, J. M., Hartung, H. P., Rose, C. R., et al. (2011). A new role for interferon gamma in neural stem/precursor cell dysregulation. Mol. Neurodegener. 6:18. doi: 10.1186/1750-1326-6-18

Wang, B., and Jin, K. (2014). Current perspectives on the link between neuroinflammation and neurogenesis. Metab. Brain Dis. doi: 10.1007/s11011-014-9523-6. [Epub ahead of print].

Waterhouse, E. G., An, J. J., Orefice, L. L., Baydyuk, M., Liao, G. Y., Zheng, K., et al. (2012). BDNF promotes differentiation and maturation of adult-born neurons through GABAergic transmission. J. Neurosci. 32, 14318-14330. doi: 10. 1523/jneurosci.0709-12.2012

Wu, Y. C., Williamson, R., Li, Z., Vicario, A., Xu, J., Kasai, M., et al. (2011). Dendritic trafficking of brain-derived neurotrophic factor mRNA: regulation by translin-dependent and -independent mechanisms. J. Neurochem. 116, 11121121. doi: $10.1111 / j .1471-4159.2010 .07166 . x$

Yirmiya, R. (1996). Endotoxin produces a depressive-like episode in rats. Brain Res. 711, 163-174. doi: 10.1016/0006-8993(95)01415-2

Yirmiya, R., Pollak, Y., Barak, O., Avitsur, R., Ovadia, H., Bette, M., et al. (2001). Effects of antidepressant drugs on the behavioral and physiological responses to lipopolysaccharide (LPS) in rodents. Neuropsychopharmacology 24, 531-544. doi: 10.1016/s0893-133x(00)00226-8

Zunszain, P. A., Hepgul, N., and Pariante, C. M. (2013). Inflammation and depression. Curr. Top. Behav. Neurosci. 14, 135-151. doi: 10.1007/7854_2012_211

Conflict of Interest Statement: The authors declare that the research was conducted in the absence of any commercial or financial relationships that could be construed as a potential conflict of interest.

Received: 30 September 2014; accepted: 29 November 2014; published online: 22 December 2014

Citation: Calabrese F, Rossetti AC, Racagni G, Gass P, Riva MA and Molteni R (2014) Brain-derived neurotrophic factor: a bridge between inflammation and neuroplasticity. Front. Cell. Neurosci. 8:430. doi: 10.3389/fncel.2014.00430

This article was submitted to the journal Frontiers in Cellular Neuroscience.

Copyright (c) 2014 Calabrese, Rossetti, Racagni, Gass, Riva and Molteni. This is an open-access article distributed under the terms of the Creative Commons Attribution License (CC BY). The use, distribution and reproduction in other forums is permitted, provided the original author(s) or licensor are credited and that the original publication in this journal is cited, in accordance with accepted academic practice. No use, distribution or reproduction is permitted which does not comply with these terms. 